\title{
INTERPOLATIONS OF SCHWAB-BORCHARDT MEAN
}

\section{ALFRED WITKOWSKI}

Abstract. For two means $M, N$ satisfying $M(x, y) \leqslant N(x, y)$ we apply the 'borchardtisation' process to obtain a new mean

$$
S B_{M, N}=\frac{\sqrt{N^{2}-M^{2}}}{\arccos (M / N)} .
$$

We use some geometric ideas to prove inequalities between the three means. In particular some new inequalities for Seiffert means are established.

Mathematics subject classification (2010): 26D15.

Keywords and phrases: Seiffert mean, Schwab-Borchardt mean, power means.

\section{REFERENCES}

[1] B. C. CARLSSON, Algorithms involving arithmetic and geometic means, Amer. Math. Monthly 78 (1971), 496-505.

[2] Y.-M. ChU, Y.-F. QIU, M.-K. WANG, AND G.-D. WANG, The optimal convex combination bounds of arithmetic and harmonic means for the Seiffert's mean, J. Inequal. Appl., Volume 2010 (2010), Article ID 436457, 7 pages, doi:10.1155/2010/436457.

[3] P. A. HÄstö, A Monotonicity Property of Ratios of Symmetric Homogeneous Means, J. Ineqal. Pure and Appl. Math. 3, 5 (2002), Article 71.

(Online: http://www.emis.de/journals/JIPAM/article223.html?sid=223).

[4] P. A. HÄstÖ, Optimal inequalities between Seiffert's mean and power means, Math. Inequal. Appl. 7, 1 (2004), 47-53.

[5] A. A. Jager, Solution of Problem 887, Nieuv Arch. Wisk. 4, 12 (1994), 230-231.

[6] E. Neuman, J. SÁndor, On the Schwab-Borchardt Mean, Math. Pannon. 14, 2 (2003), 253-266. (Online:

http://ttk.pte.hu/mii/html/pannonica/index_elemei/mp14-2/mp14-2-253-266.pdf).

[7] H. LiU and X-J. Meng, The Optimal Convex Combination Bounds for Seiffert's Mean, J. Inequal. Appl. 2011, 1, 44, doi:10.1186/1029-242X-2011-44.

[8] J. SÁndor, On certain inequalities for means, II, J. Math. Anal. Appl. 199, 2 (1996), 629-635.

[9] J. SÁNDOR, On certain inequalities for means, III, Arch. Math. (Basel) 76 (2001), 34-40.

[10] J. SÁNDOR, Über zwei Mittel von Seiffert, Die Wurzel 5 (2002), 104-107.

[11] J. SÁNDOR, E. NeUman, On certain means of two arguments and their extensions, Int. J. Math. Math. Sci. 2003, 16 (2003), 981-993, doi:10.1155/S0161171203208103 .

[12] J. SÁNDOR, T. TRIF, Some new inequalities for means of two arguments, Int. J. Math. Math. Sci. 25, 8 (2001), 525-532, doi:10.1155/S0161171201003064

[13] H.-J. SEIFFERT, Werte zwischen dem geometrischen und dem arithmetischen Mittel zweier Zahlen, Elem. Math. 42 (1987), 105-107.

[14] H.-J. SeIfFerT, Problem 887, Nieuw Arch. Wiskd. (Ser. 4) 11 (1993), 196.

[15] H.-J. SEIFFERT, Aufgabe $\beta$ 16, Die Wurzel 29 (1995), 221-222.

[16] H.-J. SEIFFERT, Ungleichungen für einen bestimmten Mittelwert, Nieuw Arch. Wiskd. (Ser. 4), 13 (1995), 195-198.

[17] S. WAng, Y. CHU, The Best Bounds of the Combination of Arithmetic and Harmonic Means for the Seiffert's Mean, Int. J. Math. Anal. 4, 22 (2010), 1079-1084. 
[18] C. Zong, Y. Chu, An Inequality Among Identric, Geometric and Seiffert's Means, Int. Math. Forum 5, 26 (2010), 1297-1302. 